\title{
AUSENCIA Y MUERTE PRESUNTA EN EL CODIGO CIVIL DE 1984
}

Carlos Enrique Becerra Palomino

\section{INTRODUCCION}

En los Códigos Civiles de 1836, 1852 y 1936 se había regulado el régimen de la ausencia y la muerte presunta, aunque no diferenciando claramente las etapas. El Código Civil de 1984 considera dos etapas tratándose de la ausencia: a) desaparición, y b) declaración de ausencia. (Libro I, Título VI). Fernández Sessarego afirma que se trata de una innovación sistemática en nuestra normatividad civil y que obedece en "alguna medida a una inspiración nativa"; no obstante, reconoce las influencias externas, como lo veremos en el desarrollo del presente ensayo $(*)$. Es importante señalar la posición singular que tiene este cuerpo de leyes frente a la legislación comparada ya que regula la declaración de muerte presunta en el mismo título que trata de la muerte real (Título VII).

Asimismo, es pertinente hacer notar la explicación dada por la Comisión Revisora en la Exposición de Motivos, tratándose de la muerte presunta: "Esta regulación se hace aún más necesaria si se tiene en cuenta el agreste territorio patrio, la circunstancia de que en nuestro País se producen cada cierto tiempo desastres naturales y la eventual situación de operaciones bélicas" (**).

(*) FERNANDEZ SESSAREgo, Carlos. Derecho de las Personas. Librería Studium, Lima, Perú, p. 115.

(**) El Peruano. Separata especial, martes 12 de marzo de 1991, p. 5. 
Este ensayo consta de tres capitulos: el primero trata los aspectos generales acerca de la ausencia y la muerte presunta, el segundo sobre los antecedentes en nuestra legislación, y el tercero se orienta hacia un análisis del Código Civil de 1984.

\section{CAPITULO I: ASPECTOS GENERALES}

\section{Ausencia}

\subsection{Noción y contenido}

En sentido material o común la ausencia es una falta de presencia. Sin embargo, jurídicamente, tiene otra connotación. Serrano y Serrano la define como "un estado civil de la persona de quien se duda si vive, bien porque se desconoce su paradero durante cierto tiempo, bien porque desapareció en una circunstancia de peligro para la vida sin haberse vuelto a saber más de ella". Dicho autor señala que la verdadera esencia de la ausencia radica en la incertidumbre acerca de la persona ausente (1). Rescigno tiene idéntico parecer: "Es decisiva - dice - la ignorancia sobre el hecho mismo de la existencia de la persona, más que la ignorancia del lugar donde ella se encuentra" (2).

Diez-Picazo y Gullón niegan que se trate de un estado civil, ya que la ausencia no modifica la capacidad del ausente, pero están de acuerdo en la duda sobre la existencia de la persona: "El ausente,

(1) SERRANO Y SERRANO, Ignacio. La ausencia en el Derecho Espanol. Revista de Derecho Privado. Madrid. 1943. p. 1 y p. 86. Moisset de Espanés recalca que frente al concepto amplio de ausencia tenemos la ausencia en sentido técnico: "calificada por alguna circunstancia particular, en virtud de la cual la ley atribuye determinadas consecuencias jurídicas". MOISSET DE ESPANES, Luis. Ausencia y desaparición. En: Jurisprudencia Argentina. Buenos Aires, 1975. Junio 12, p. 1.

(2) RESCIGNO, Pietro. Manuale del diritto privato italiano. Napoli, Casa Editrice Eugenio Jóvene, 1984, p. 133. 
jurídicamente expresado, es una persona que no sabemos si existe ni donde existe". Para los Mazeaud, "es el individuo del que no se sabe si está vivo o muerto (3). Espín asevera que ausente, en sentido técnico, "es el que desapareció, ignorándose su paradero y dudándose de su existencia; la ausencia exige, pues, la incertidumbre absoluta sobre la existencia de una persona (an sit et ubi sit) (4). Ogáyar y Ayllón descarta la idea de peligro tratándose de la desaparición e incide en que ésta se haya producido en circunstancias normales. Albaladejo menciona la carencia de noticias y Castán señala que la ausencia propiamente dicha "es la del que se halla fuera de su domicilio desconociéndose su paradero y su existencia" (5).

A lo expuesto debe agregarse el hecho de que no exista repre-. sentante con facultades suficientes, ya que de haberlo se presume que la persona previó su alejamiento por alguna circunstancia especial.

En consecuencia, tal como lo hemos señalado en otra oportunidad (6), la ausencia se refiere a la situación de una persona que:

(3) DIEZ-PICAZO, Luis y GULLON, Antonio. Sistema de Derecho Civil. Volumen I. Editorial Tecnos, Madrid, 1989, p. 302.

MAZEAUD, Henry, Leon y Jean. Lecciones de Derecho Civil . Buenos Aires, Ediciones Jurídicas Europa América, 1965. P. I, Tomo I, Vol. II, p. 13.

(4) ESPIN, Diego. Manual de Derecho Civil Español. Volumen I - Parte General. Editorial Revista de Derecho Privado. Editoriales de Derecho Reunidas. Madrid, 1982. P. 351.

(5) OGAYAR Y AYLLON, Tomás. La Ausencia en Derecho Sustantivo y Adjetivo. Madrid, Editorial REUS S.A. 1936, p. 6. ALBALADEJO, Manuel. Curso de Derecho Civil. Introducción y Parte General. Barcelona, Bosch, 1983. CASTAN TOBEÑAS, José, Derecho Civil Español y Foral. 14a. edición. Revisada por José Luis de los Mozos. Madrid. REUS S.A. 1987. Tomo I. Vol. II. pp. 32-321. Véase también OGAYAR Y AYLLON, Tomás y LETE DEL RIO, José Manuel. Comentarios al Código Civil y Compilaciones Forales. Dirigidos por Manuel Albaladejo. Segunda Edición. Madrid. Editorial Revista de Derecho Privado 1985. Tomo IV, p. 2.

(6) Véase nuestro artículo: La ausencia y sus efectos en relación con la 
a) No se encuentra en el lugar de su domicilio,

b) Se ignora su paradero,

c) Carece de representante suficientemente facultado; y

d) Respecto de quien puede llegar a dudarse sobre su existencia con el transcurso del tiempo.

\subsection{Etapas}

La doctrina y la legislación comparada no son uniformes en el tratamiento de la ausencia: las etapas o períodos varían en número y denominación. Como asevera Marinella Essu, la doctrina predominante considera a la declaración de ausencia como situación de derecho, frente a la desaparición que es entendida como situación de hecho (7). En lo que se refiere a la desaparición, existen diversas concepciones doctrinarias considerándola como institución indepen- diente vinculada a las situaciones de catástrofe o te peligro para la vida, asimilándola a la ausencia, utilizándose ambos términos indistintamente, y como una etapa de la ausencia pero diferenciada de la declaración de la misma (este criterio es seguido por la mayoría de autores contemporáneos y es la tendencia de la legislación comparada más reciente).

Los elementos de la desaparición son, en resumen: a) falta de presencia en el lugar del domicilio o residencia; b) ignorancia del paradero de la persona o carencia de noticias; y c) inexistencia del representante con facultades suficientes.

familia. En: DE TRAZEGNIES GRANDA, Fernando; RODRIGUEZ ITURRI, Roger; CARDENAS QUIROS, Carlos; GARIBALDI, José Alberto (Editores). La Familia en el Derecho Peruano. Libro Homenaje al Dr. Héctor Cornejo Chávez. Fondo Editorial de la Pontificia Universidad Católica del Perú, Lima 1990. pp. 481 y sgts.

(7) ESSU, Marinella. L'Assenza e la Dichiarazione di Morte Presunta. En: Tratatto di Diritto Privato. D. RESIGNO, Pietro. Torino: Utet, 1982. Tomo 2, pp. 435-436. 
La desaparición no requiere una declaración judicial, sino que configurada ésta, de acuerdo a los elementos antes señalados, se procede al nombramiento de alguien que se haga cargo de los asuntos de la persona desaparecida.

Tratándose de la Declaración de Ausencia, la mayoría de los autores se refieren a ella como el segundo periodo de la institución de la ausencia, en la cual adquiere su sentido técnico.

Dicha declaración de ausencia se configura, en síntesis: a) por la desaparición, b) la incertidumbre sobre la existencia (por el transcurso del tiempo); y c) la resolución judicial (8).

Como puede apreciarse en el CODE, el BGB, el Código Civil y Comercial italiano y otros códigos europeos, así como en los códigos chileno, argentino, brasileño y otros códigos latinoamericanos, el tratamiento es dispar, como lo veremos a continuación.

El CODE distingue tres períodos: la presunción de ausencia, la ausencia declarada y la posesión definitiva. Sin embargo, en el modelo francés el desaparecido es aquél cuya desaparición se produjo en circunstancias de grave peligro para su vida (por lo cual "existe casi la certeza de que ha muerto"), en tanto que el ausente es "el individuo que no se sabe si está vivo o ha muerto", como aseveran los Mazeaud (9).

El BGB o Código Civil alemán prevé: a) curatela de ausentes (art. 1911), según la cual "el mayor de edad ausente cuyo paradero es desconocido tendrá un curador para sus asuntos patrimoniales siempre que sea necesario ocuparse de éstos"; y b) declaración de muerte por razón de ausencia, en la que cabe distinguir la ausencia en general, derivada de la carencia de noticias durante un lapso prolon-

(8) Para mayor información sobre este particular, véase nuestro citado artículo de la nota 6, parágrafos 1.2.1 y 1.2.2., así como las notas.

(9) MAZEAUD, Henry, León y Jean. Lecciones de Derecho Civil. Parte I. Buenos Aires. Ed. Jurídicas Europa América, 1965, Vol. II, pp. 12 y ss. 
gado (art.14), y la ausencia calificada (arts. 15 al 17) en los casos de desaparición en circunstancias de peligro para la vida (10).

El Código Civil y Comercial italiano de 1942 considera tres etapas: desaparición (cuyo efecto es el nombramiento de un curador), la declaración judicial de ausencia (que determina la posesión temporal de los bienes del ausente a sus sucesores) y la declaración de muerte presunta (que les concede el ejercicio de los derechos sucesorios) (11).

En el Código Civil español puede observarse tres etapas: la ausencia de hecho, la ausencia legal y la declaración de fallecimiento. El texto original del Título VIII de dicho código, de 1889, fue modificado por las leyes de 8 de setiembre de 1939, No. 11/1981, de 13 de mayo, y No. 30/1981, de 7 de julio. El Código Civil suizo contempla la curatela en caso de ausencia (arts. 392 y 393) y la declaración de desaparición, según la cual es posible hacer valer los derechos derivados de la muerte del desaparecido como si ésta hubiese sido probada (arts. 35 a 38). El Código Civil portugués norma la ausencia en tres períodos: curatela provisoria, curatela definitiva y muerte presunta (arts. 89 a 121).

El Código chileno regula la ausencia dentro de la "Presunción de muerte por desaparecimiento", distinguiéndose la mera ausencia, la posesión provisoria y la posesión definitiva. El Código Civil argentino, según la modificación de la Ley 14.394, distingue: un período de declaración de ausencia, en el que se designa curador de bienes al desaparecido (arts. 15 al 21), y la declaración de ausencia con presunción de fallecimiento, cuyo efecto principal es dar lugar a la apertura de sucesión del ausente (arts. 22 al 33). El Código brasileño establece: curatela de ausentes (nombramiento de curador de bienes), sucesión provisoria (apertura provisoria de sucesión con prestación de garantías) y sucesión definitiva (se levantan las garantías).

(10) ENNECERUS, KIPP Y WOLF. Tratado de Derecho Civil. Barcelona. Bosch, 1979. T. IV - 2. p. 448 y ss.

(11) MESSINEO, Francesco. Manual de Derecho Civil y Comercial. Buenos Aires. Ediciones Jurídicas Europa América, 1979. Tomo II, pag. 136. 
Respecto a otros códigos de latinoamérica, quisiéramos hacer mención a los siguientes: el Código Civil boliviano regula dos situaciones: la declaración de ausencia (que incluye el nombramiento de curador) y la declaración de fallecimiento presunto. El Código Civil de Costa Rica prevé medidas provisionales anteriores a la declaración de ausencia (nombramiento de un curador), la declaración de ausencia (posesión provisional de bienes), y la presunción de muerte (permite la posesión definitiva de los bienes). Los códigos más recientes, como el de Paraguay (1987) y el de Cuba (1988), consideran: el primero, curatela de bienes para la persona que se ausente o desaparezca de su domicilio (art. 272) y la declaración de desaparición con presunción de fallecimiento, que da lugar a la posesión definitiva de los bienes (arts. 63 a 72); y el segundo, la declaración judicial de ausencia (que da lugar a la designación de un representante) y la declaración de muerte presunta (que permite a los interesados ejercitar los derechos que les correspondan a la muerte del desaparecido, con las particularidades inherentes al sistema jurídico vigente en Cuba) (12).

En el Perú, tal como lo hemos señalado, tratándose de la ausencia el Código Civil prevé dos etapas: a) desaparición; y b) declaración de ausencia. La muerte presunta está regulada en el Título relativo a la muerte.

\section{Declaración de muerte presunta}

\subsection{Concepto}

La primera regulación sistemática sobre la declaración de muerte presunta - también denominada declaración de fallecimiento, ausencia con presunción de fallecimiento o presunción de muerte por desaparecimiento- la hace el Código Civil alemán (BGB), que prevé

(12) BECERRA PALOMINO, Carlos Enrique. "La Ausencia y la Declaración de Fallecimiento en el Código Civil Español y en la Codificación Latinoamericana". Ponencia presentada en el Seminario Internacional sobre el Código Civil Español como puente de unión entre el derecho europeo y el derecho latinoamericano. Burgos, 1989 (en prensa). 
dicha declaración tanto para el caso de ausencia prolongada de una persona, cuanto para el de su desaparición en circunstancias de peligro grave para la vida (13).

Para García Amigo, la declaración de muerte presunta "es una resolución judicial obtenida al final de un expediente o procedimiento de jurisdicción voluntaria y que crea la situación jurídica de muerte presunta -no la muerte real". Albaladejo entiende por declaración de fallecimiento, "al auto judicial que reputa muerto a un desaparecido". Diez Picazo y Gullón señalan que la declaración de fallecimiento "es aquella situación jurídica, creada por medio de una resolución judicial, por virtud de la cual se califica a una persona desaparecida como fallecida, se expresa la fecha a partir de la cual se considera ocurrida la muerte de la persona, y se abre la sucesión de la misma" (14).

De lo antes expuesto, podemos definir a la declaración de muerte presunta como la resolución judicial por la cual, verificada la ocurrencia de ciertos hechos expresamente señalados en la ley, se tiene por muerta presuntamente a una persona, del mismo modo que si se hubiera comprobado su muerte, mientras no sea destruída la presunción.

(13) Somarriva Undurraga asevera que el Código Civil chileno de 1855 fue el precursor en materia de muerte presunta, pues siendo anterior al Código alemán reguló esta figura en forma muy completa. Señala además que Bello se inspiró, conforme a la nota a los arts. 83 a 85 de su Proyecto de 1853, en el Código Civil austríaco, aunque este último tenia una reglamentación muy incompleta. (SOMARRIVA UNDURRAGA, Manuel. Evolución del Código Civil Chileno. Bogotá. Editorial Temis Librería. 1983. p. 12).

(14) GARCIA AMIGO. Manuel. Instituciones de Derecho civil. I. Parte General. Madrid. Editorial Revista de Derecho Privado. 1979. p. 355. ALBALADEJO, Manuel. Curso de Derecho Civil Español. Barcelona. Librería Bosch. T. I. p. 206. DIEZ PICAZO, Luis y GULLON, Antonio. Sistema de Derecho Civil. Madrid, Tecnos. 1980. Vol. I. p. 338. 


\subsection{Contenido y efectos}

Michele Giorgianni afirmaba que “... los efectos de la declaración de muerte presunta son perfectamente idénticos, ya sea en cuanto al contenido, ya sea en cuanto a la estructura, que los de la muerte natural". Messineo expresa que ella tiene efectos provisionales pero de naturaleza análoga a los que se tendrían en caso de la muerte comprobada. Somarriva Undurraga asevera que la declaración de muerte presunta "pone fin a la personalidad produciendo los mismos efectos de la muerte real" (15).

Fernández Sessarego dice que "la declaración de muerte presunta produce todos los efectos jurídicos de la muerte natural" (16). Tobias señala que "una muy firme probabilidad (que no es certeza) es valorada como elemento de juicio que permite 'considerar' al sujeto en la condición de muerto para la ley" (17), y estimando que la sentencia que declara la muerte presunta afecta la existencia misma de la persona: "un ser humano determinado que hasta entonces era persona de derecho, deja de serlo" (18).

Cabe tener presente, sin embargo, que el sujeto declarado presuntamente muerto puede encontrarse con vida en otro lugar (gozan-

(15) GIORGIANNI, Michele. L'a Dichiarazione di Morte Presunta. Milano. Dott. A. Giuffre - Editore. 1943. pag. 196. MESSINEO, Francesco. Ob. Cit. T. II. pag. 141. SOMARRIVA UNDURRAGA, Manuel. Ob. Cit. pag. 11.

(16) FERNANDEZ SESSAREGO, Carlos. Ob.Cit. p. 134. Jack Bigio, por su parte, ha afirmado que "la muerte presunta, como efecto principal pone fin a la persona". BIGIO CHREM, Jack. Declaración de Muerte Presunta y Reconocimiento de Existencia en el Código Civil de 1984. En: Libro Homenaje a Mario Alzamora Valdez. Cultural Cuzco S.A. Lima, 1988, p. 63.

(17) TOBIAS, José W. Fin de la existencia de las personas fisicas. Ed. Astrea de Alfredo y Ricardo de Palma. Buenos Aires 1988, p. 108.

(18) TOBIAS, José W. Ob. Cit. p. 108. SALVAT, Raymundo. Tratado de derecho civil argentino. Parte general. 11a. ed., actualizada por J.M. López Olaciregui. Tea. Buenos Aires, 1964. T. I, No. 96-A. p. 895. 
do de plena capacidad), pues, como asevera Albaladejo, la declaración de fallecimiento "afecta a la situación jurídica del sujeto, no en el lugar en el que, si vive, está, sino en el círculo jurídico de donde falta" (19).

En cuanto al aspecto patrimonial el principal efecto de la declaración de muerte presunta es la apertura de la sucesión, aunque algunas legislaciones prefieren referirse a una "posesión definitiva" de bienes. En cuanto a la esfera familiar, es necesario destacar las diferentes soluciones dadas por las legislaciones respecto del vínculo matrimonial del declarado muerto presunto, como podrá observarse más adelante.

La declaración de muerte presunta se sustenta en una presunción "juris tantum", que puede ser enervada. En primer lugar, es posible que quien se consideraba muerto no lo esté en realidad y que, luego de la declaración, reaparezca o dé muestras inequívocas de su existencia (aun estando en lugar lejano). En segundo lugar, la presunción puede ser destruida por la comprobación de la muerte real, sea en la misma fecha o en una distinta a la señalada en la resolución que declara la muerte presunta.

\section{CAPITULO II: ANTECEDENTES EN NUESTRA LEGISLACION CIVIL}

El Derecho Civil peruano ha regulado a través de todas sus codificaciones el régimen de la ausencia y la presunción de muerte, aunque no se diferenciaba claramente las etapas.

1. Proyecto de Vidaurre (20)

El proyecto en varios artículos se refiere directa e indirecta-

(19) ALBALADEJO, Manuel. Ob. Cit. T. I. p. 208.

(20) El Proyecto de Código Civil elaborado por Manuel Lorenzo de Vidaurre es de fundamental importancia como el primer intento codificador de la vida republicana en el Perú. Este proyecto se originó a raíz de un 
mente a la ausencia y a la presunción de muerte, pero carece de una regulación sistemática sobre estas materias.

La curatela de bienes del ausente (entendiéndose que carece de representante) está prevista en el art. 27 del Título 14: "se dará un curador a los bienes de los ausentes e intestados, si se hallan en abandono" (21). Las facultades de dicho curador son idénticas a las de los tutores (art. 26, título 14), es decir, guardar y defender la persona y los bienes del sujeto a curatela (art. 1, título 14), evitar con el mayor esmero su ruina y detrimento (art. 13, título 14). Asimismo, estaba prohibido de enajenar tales bienes, salvo el caso de necesidad absoluta, previo informe del consejo de familia, dictamen fiscal y orden judicial (art. 16, título 14).

El término ausencia es empleado en el artículo 25 del título $1^{\circ}$ denominado "De esponsales": se rompen los esponsales "por ausencia de uno de los contrayentes, sin aviso y permiso del otro, pasados dos años" (22).

Vidaurre expresa haber tomado esta norma de las Siete Partidas. En efecto, en la Partida Cuarta, Título I, Ley VIII, se establece como una de las causales para "embargar o desfazer los Desposorios": "quando alguno dellos desposados se va a otra tierra, e non lo pueden

artículo de la Constitución de 1834 que facultaba a la Corte Suprema a presentar proyectos de Códigos, empezando por el Civil. Vidaurre, calificado como un "personaje indudablemente exótico, contradictorio, con una vida intensa" (DE TRAZEGNIES GRANDA, Fernando. La Idea de Derecho en el Perú Republicano del Siglo XIX. Lima. Fondo Editorial de la Pontificia Universidad Católica del Perú. 1979. P. 155), presidía la Corte Suprema en ese momento y, según Basadre, "conocía a fondo, como los jurisconsultos surgidos en la época de los códigos no han conocido, el Derecho Romano, el Canónico y el español". BASADRE, Jorge. Historia del Derecho Peruano. II Edición. Lima. Edigraf S.A. 1984. P. 330.

(21) VIDAURRE, Manuel Lorenzo. Proyecto de Código Civil Peruano. Lima. Imprenta del Constitucional por Lucas Lama. 1834. Tomo I. P. 278.

(22) Ibidem. P. 4. 
fallar, nin saber do es". En tal caso el otro debía esperar tres años para pedir la licencia que le permita casarse. Vidaurre recalca que él ha considerado dos años. Asimismo, afirma que "por su literal sentido la ausencia, sin previa noticia, es razón suficiente para disolver el pacto" (23).

En el Título Segundo, denominado "De Matrimonio", el art. 33 está relacionado con la ausencia y la muerte presunta: "no se puede proceder a un segundo matrimonio sin prueba completa de la muerte del cónyuge" (24). Vidaurre afirma que "si los matrimonios se tienen por absolutamente indisolubles, cualesquiera que sea el tiempo de la ausencia, ella no habilita para proceder a un segundo matrimonio" (25).

En el Título Cuarto, denominado "Dotes, donaciones, propter nupcias, arras gananciales", el art. 25 establece que "el marido puede ser separado de la administración de los bienes por impedimentos morales o físicos".

El autor señala haber tomado su proyecto de las leyes de la Novísima, copiadas de las de Toro y Castilla. Al respecto, expresa que "como sea justo que la muger sea habilitada a contratar y administrar en caso de resistencia o ausencia del marido, mucho más lo será cuando su estado no le permita encargarse de ningún negocio interior o exterior de la familia" (26).

En el Título Noveno, denominado "Procedimientos en causas de filiación", encontramos el término ausencia en el art. 9o., que establece: "los términos para la demanda contra la filiación son perentorios.

(23) Ibidem. p. 25. LOPEZ, Gregorio. Las Siete Partidas del muy Noble Rey don Alfonso El Sabio. Tomo II. Madrid, Compañía General de Impresores y Libreros del Reino. 1843, p. 473.

(24) VIDAURRE, Manuel Lorenzo. Ob.Cit. P. 31.

(25) Ibidem. P. 83.

(26) VIDAURRE, Manuel Lorenzo. Ob.Cit. P. 143. 
Para que concluidos se admita, ha de darse prueba completa de ausencia o ignorancia".

Lamentablemente este título del proyecto no ha sido comentado por el autor. Sin embargo, puede apreciarse que se considera a la ausencia (debidamente probada) como una excepción en cuanto al cómputo de los plazos establecidos para contestar la paternidad, en razón de la imposibilidad del ausente para accionar.

El artículo 60. del Título 12, denominado "De la potestad en la familia, derechos y obligaciones del padre, de la madre, de los hijos: de la ex-heredación: del tribunal de la familia: de los domésticos", establece, como regla general, que la autoridad de la madre está subordinada al padre mientras éste se encuentre con vida y en ejercicio de sus derechos. Pero, "muerto el padre o impedido por obstáculos físicos o morales, la autoridad queda íntegra en la madre" (27).

Aunque Vidaurre no lo dice expresamente, la ausencia del padre sería un obstáculo que le impediría ejercer su autoridad y, en consecuencia, ésta pasaría a la madre.

Como puede observarse, el Proyecto Vidaurre hizo referencia a la ausencia a través de su articulado aunque sin hacer una regulación específica de la institución ni establecer en qué casos debe considerarse a una persona como ausente.

\section{El Código Civil Nor Peruano de 1836 (28)}

El Código de Santa Cruz trata en forma amplia la materia que estamos estudiando: 28 artículos, desde el artículo 55 hasta el 83,

(27) Ibidem. P. 221.

(28) Durante la Confederación Perú-Boliviana, Andrés de Santa Cruz, por Decreto de $1^{\circ}$ de noviembre de 1836, puso en vigencia el Código Civil, que conjuntamente con los Códigos Penal y de Procedimientos fueron calificados como "Códigos Bolivianos" y no tuvieron aceptación en el 
dentro del Título IV denominado "De los Ausentes", en el Libro I "De las Personas".

Este código contempla dos momentos: la ausencia presunta y la declaración de ausencia, así como algunos efectos de la muerte presunta tales como la posesión definitiva de los bienes, extinción de la fianza, etc. Podemos afirmar, en consecuencia, que está regulada la ausencia en tres fases - aunque no explícitamente determinadas-: la presunta ausencia (desaparición), la declaración de ausencia y la muerte presunta.

El código no define la ausencia presunta, simplemente alude a la necesidad de nombrar administrador de bienes, de no existir apoderado. Esta designación se hace por el juez de oficio o a pedido de los interesados (artículo 55). Asimismo, a pedido de la parte más diligente se nombra "apoderado" que represente al presunto ausente en inventarios, cuentas, particiones, y liquidaciones (artículo 56). Estos procedimientos se deben realizar con participación del Ministerio Público, según lo señala el artículo 57.

Este código contempla expresamente la declaración de ausencia, estableciéndose en el artículo 58 los presupuestos necesarios, esto es, que "una persona no aparezca en el lugar de su domicilio, o en el de su residencia, y después de cuatro años no haya noticias acerca de ella (...)".

El efecto de esta declaración es dar en posesión provisional los bienes del ausente si no hay administrador de bienes nombrado por éste. Pero si existe apoderado deben transcurrir diez años para poder solicitar la declaración de ausencia (ya que la existencia de apoderado implica que la persona ha previsto su ausencia). Otro efecto es la apertura del testamento del ausente, con la finalidad de que todos

Perú, para ser derogados por Orbegoso por decreto del 31 de julio de 1838. TRAZEGNIES GRANDA, Fernando. Ob.Cit., pag. 159 y 160. Refiriéndose al Código Civil dice Basadre, "Este Código viene a significar, en su mayor parte, una recepción mecánica del Código Francés. No lo es, sin embargo, en varios títulos fundamentales". BASADRE, Jorge. Ob.Cit. P. 345. 
aquellos que tengan derechos a partir de la muerte de éste obtengan la posesión provisional de los bienes. El cónyuge podrá oponerse a esta posesión, y los que la adquieran tendrán que hacer inventario y sólo podrán enajenar los bienes con autorización del juez.

Cabe resaltar que de acuerdo al artículo 61: "no se pronunciará el juicio de ausencia, sino después que hubiese ordenado y verificado la información".

El artículo 67 establece que la posesión provisional no será sino un depósito sobre los bienes sujetos a administración. Sin embargo, en el artículo 69 se permite la posibilidad de disfrute, pues se refiere a "Tos que a consecuencia de la misión hubiesen disfrutado de los bienes del ausente". En tal caso, éstos sólo estarán obligados a devolver un quinto de los frutos si el ausente aparece a los 15 años y un décimo si aparece con posterioridad. Luego de 30 años sólo deberán devolver los bienes, sin obligación de devolver los frutos.

Si el ausente reaparece durante la posesión provisoria cesan los efectos del juicio de declaración de ausencia (art. 74).

Si la ausencia ha continuado durante 30 años desde la misión provisoria o de la administración de los bienes del ausente por su cónyuge, o si han transcurrido 100 años desde el nacimiento del ausente, terminan las fianzas y quienes tienen derecho pueden pedir la partición de los bienes y solicitar la misión posesoria definitiva (art. 71).

No obstante, se establece que la sucesión del ausente tendrá lugar el día que se pruebe su muerte (art. 72), lo cual indica que en este Código no se llega nunca a presumir la muerte de una persona ausente (como ocurre en el Código Napoleón, cuya influencia es notoria).

En la hipótesis de la reaparición del ausente, o de la prueba de su existencia, éste recobra sus bienes en el estado en que se encuentren, el precio de los que hubiesen sido enajenados, o los bienes provenientes del empleo que se hubiese hecho del precio de sus bienes vendidos (art. 75). 


\section{El Código Civil de 1852 (29)}

La ausencia se encuentra regulada en el Libro 1 "De las Personas y sus Derechos", en el Título III denominado "De los vecinos y ausentes", desde el artículo 56 al 82 (26 artículos). Para Javier de Belaunde, este Código "traía un tratamiento de la materia bastante sistemático y ordenado que explica el tratamiento de los ausentes y los guardadores de bienes de ausentes que trae el Código de Procedimientos Civiles de 1912" (30).

Angel Gustavo Cornejo (31) expresa que de acuerdo a estas normas pueden distinguirse cuatro períodos en la ausencia:
a) Presunción de ausencia.
b) Ausencia legal.
c) Presunción de vida.
d) Presunción de muerte.

(29) Este Código se originó con una ley promulgada por el Presidente Castilla el 9 de octubre de 1845, en la cual se creaba una comisión codificadora, siendo su texto final el fruto de tres comisiones, el cual fue promulgado el 28 de julio de 1852, durante el gobierno de Echenique. Con relación a las ideas que inspiraron este Código, Basadre señala, en primer lugar, la influencia romanista que atribuye al movimiento filosófico "jus naturalista"; en segundo lugar, la influencia española, primordialmente de la antigua legislación castellana; asimismo, destaca la influencia francesa, expresando que si bien para algunos hay una "recepción mecánica" del Código francés, las diferencias entre ambos "son resaltantes en múltiples tópicos", entre los cuales menciona el caso de la ausencia; finalmente, se refiere a la influencia del derecho canónico y del Código Santa Cruz. BASADRE, Jorge. Ob.Cit. Pp. 362-373.

(30) DE BELAUNDE, Javier. Exposición del Doctor Javier de Belaunde López de Romaña sobre el Libro I del Código Civil de 1984; Derecho de las Personas. En: El Derecho. Arequipa. Organo del Colegio de Abogados de Arequipa. 1985. P. 120.

(31) CORNEJO, Angel Gustavo. Comentario al Código Civil de 1852. Chiclayo, Dionisio Mendoza, 1921.P. 69. 
El Código de 1852 no se refiere expresamente a la desaparición, pero el período de la presunción de ausencia es el que está relacionado con esta figura.

En este periodo se emplea el término ausente tanto en el sentido de "no presente", como en su sentido jurídico. Esto lo podemos apreciar en los artículos 56, 57 y 58. En ellos se habla del ausente sin existir ignorancia sobre el paradero de la persona (artículo 56), siendo mas bien conocido su paradero. En un caso dentro de la República (artículo 57), y en otro fuera de ella.

El artículo 58 sí se refiere al ausente en sentido jurídico, tal como se aprecia de su parte final: "Lo mismo se verificará con el ausente cuyo domicilio se ignora".

Para Toribio Pacheco resulta cuestionable el criterio de este Código de distinguir entre tres tipos de ausencia: 1) los que se hallen fuera de su domicilio ordinario, pero dentro de la República y en lugar conocido; 2) los que se hallen fuera de la República en lugar también conocido; y 3) aquellos cuyo domicilio se ignora absolutamente, dentro o fuera de la República. He aquí las palabras del destacado jurista:

"Esta distinción no puede apoyarse en ningún fundamento plausible, que no se alcanza la razón por qué el ausente fuera de la república, pero cuyo punto de residencia se conoce, ha de ser peor o mejor condición que el ausente que se halla dentro del territorio de la república" (32).

Pacheco califica de "injustificable y absurda" la asimilación que se hace entre el ausente que se encuentra fuera de la República sin apoderado, cónyuge, ni hijos, con el ausente propiamente dicho, debido a que se confunde "a un individuo cuya existencia es un hecho real, positivo y notorio, con otro cuya vida o muerte son, por lo menos, problemáticas (...)" (33).

(32) PACHECO, Toribio. Tratado de Derecho Civil . Lima, Imprenta del Estado. 1872. Tomo I. P. 139.

(33) Ibidem. P. 142. 
Cornejo, igualmente, critica el empleo del término "ausente", señalando que "si uno se aleja del lugar de su domicilio pero se sabe donde está, no debe considerársele ausente (...). La distinción entre ausente dentro de la República y ausente fuera de ella, no tiene importancia alguna" (34).

Los únicos casos en los que cabe la designación de guardador son los previstos en el art. 58. En primer lugar, cuando el ausente está fuera de la República sin apoderado, cónyuge ni hijos. En segundo lugar, en el caso del ausente cuyo domicilio se ignora, es decir, el ausente en sentido estricto.

Las facultades del guardador están señaladas en el art. 62 y son puramente de administración, con la prohibición de enajenar los inmuebles. Tratándose de muebles éstos sólo podrán enajenarse con autorización judicial.

Como puede apreciarse, no se contempla la posibilidad de enajenar o gravar los inmuebles ni aun con autorización judicial por necesidad o utilidad. Esta prohibición absoluta no está justificada.

La terminación del cargo de guardador se produce, según el artículo 65:

1. Cuando vuelve el ausente o constituye apoderado.

2. Cuando se da la posesión provisional a los herederos del ausente.

3. Cuando renuncia o es removido.

El Código Civil de 1852, si bien no prescribe una declaración de ausencia expresamente en la regulación de esta institución, en el artículo 67 establece el otorgamien to de la posesión provisional de los bienes del ausente a sus herederos testamentarios o legales, cuando no se tiene, durante diez años, noticia alguna de aquél.

La posesión provisional implica la partición de bienes de la sociedad conyugal (artículo 68).

(34) CORNEJO, Angel Gustavo. Ob.Cit. P. 70. 
Se establece que quienes reciben la posesión temporal deben practicar el inventario y tasación de los bienes, dar fianza por su valor y están prohibidos de enajenar e hipotecar los inmuebles, (artículo 69). Los poseedores provisionales pueden gozar de la mitad de los frutos, debiéndose reservar la otra mitad (artículo 70).

La posesión provisional se puede hacer definitiva a solicitud de los herederos en dos casos: si se tiene la prueba de la muerte del ausente, $\mathrm{o}$ si transcurriese el tiempo suficiente para que el ausente hubiere cumplido ochenta años (artículo 71).

Obtenida la posesión definitiva, el heredero entra en el "goce de todos los derechos de sucesión" (art. 72); asimismo, los legatarios y todos aquellos que por el fallecimiento del ausente tuvieran algún derecho a sus bienes, podrán hacerlo valer contra el heredero que ha obtenido la posesión definitiva (art. 77).

Los efectos de esta posesión cesan cuando se tiene noticia de que vive el ausente (art. 79).

Es importante destacar que se presume la vida del ausente, y por tanto tiene derecho a adquirir por cualquier título, mientras no se haya dado posesión definitiva de sus bienes (art. 81). Tal disposición lleva a considerar que, si se presume la vida del ausente hasta la posesión definitiva, se presume su muerte a partir de ella.

Como podemos observar, en los artículcs 71,72 y 81 subyace la institución de la muerte presunta.

\section{Proyecto de 1890}

El Proyecto del Código Civil de 1890 contiene un título denominado "De los Ausentes", que regula este tema en 28 artículos y en el que puede apreciarse tres etapas.

Por un lado, se establece la administración de los bienes del ausente, lo cual tiene lugar cuaindo un mayor de edad se halla fuera de su domicilio seis meses cumplidos o más y no hay apoderado, no exigiéndose que se carezca de noticias sobre su paradero (art. 183). 
Por otro lado, se establece la posesión de los bienes del ausente a sus herederos testamentarios o legales en dos casos: cuando no se tiene noticia de éste durante cinco años (art. 192) y cuando la persona ausente está incursa en situaciones de peligro para su vida (art. 193).

Finalmente, alude a la muerte presunta al disponer que el poseedor de los bienes del ausente puede pedir se le declare dueño condicional de los mismos, para lo cual debe acreditar que, sin tenerse noticia cierta del ausente, ha transcurrido el tiempo suficiente para que éste haya cumplido ochenta años (art. 203).

Es importante mencionar que en este proyecto se ha previsto el caso de ausencia del menor de edad (art. 185).

\section{El Código Civil de 1936}

Con relación a los Códigos examinados anteriormente, el de 1936 es pobre en cuanto al tratamiento de la ausencia y la muerte presunta. La terminología empleada era confusa y la regulación asistemática.

La doctrina peruana es concorde en la crítica. En opinión de Rómulo Lanatta: "No se llegó por consiguiente a estructurar un sistema integral. Los artículos 590, 611 y 612 (...), son insuficientes para configurar el régimen sustantivo de la ausencia". Para Javier de Belaunde: "el tratamiento del tema de la ausencia y la desaparición y de la muerte presunta en el Código Civil del 36 es verdaderamente caótico" (35).

Fernández Sessarego señala que:

"El Código Civil de 1936 no distinguía ni los alcances ni las consecuencias jurídicas de la desaparición y de la ausencia. (...) Si, de una parte, existía en el Código Civil abrogado, con-

(35) LANATTA, Rómulo. Derecho de Sucesiones. Lima, Editorial Desarrollo S.A. 1983. P. 160. DE BELAUNDE, Javier. Ob.Cit. P. 120. 
fusión en el tratamiento de la desaparición y la ausencia, de otra, se atribuía a ambas situaciones la misma consecuencia jurídica". (36).

La desaparición se regulaba en el artículo 590 (ubicado en el libro de Derecho de Familia, en la sección de curatela, Título VI), según el cual cuando una persona se hubiere ausentado o desaparecido de su domicilio, sin conocerse su paradero y sin que exista mandatario que administre sus bienes, se proveerá a la curatela de éstos. Podemos observar que se toma como equivalentes los términos desaparición y ausencia, asignándoles los mismos supuestos y consecuencias. Sin embargo, este artículo está referido a lo que se entiende como "desaparición" en el Código vigente (art. 47).

Los elementos configurativos que contiene el artículo 590 son los siguientes:

1. Falta de presencia en el domicilio.

2. Ignorancia sobre el paradero.

3. Carencia de mandatario designado o extinción del mandato.

El efecto jurídico es la curatela sobre los bienes de la persona desaparecida, de acuerdo a lo preceptuado en los artículos 559 y 563 , relativos a las personas que deberán ejercer el cargo.

Las facultades del curador están señaladas en los artículos $\mathbf{5 8 7}$, 596 y 599 . Según ellos corresponde al curador realizar en principio actos administrativos de custodia y conservación, requiriendo autorización judicial para cualquier acto adicional, según las circunstancias.

La curatela del "ausente o desaparecido" termina en los siguientes casos:

1. Al extinguirse los bienes o desaparecer los motivos que la originaron (art. 610).

(36) FERNANDeZ SESSAREgo, Carlos. Derecho de las Personas. Lima, Lib. Studium. 1986. P. 267. 
2. Al otorgarse el goce de los derechos de sucesión a sus herederos. (arts. 611 y 612).

El Código de 1936 no contenía una regulación de la declaración de ausencia. Sin embargo, el artículo 9, inciso cuarto, señala que son absolutamente incapaces: "los desaparecidos cuya ausencia está judicialmente declarada".

Pretendiendo justificar esta norma, Rodríguez Llerena expresa:

"El incapaz está presente sin que pueda realizar actos jurídicos. El ausente no puede realizarlos por sí, ni jurídica ni materialmente, no por falta de aptitud esencial, como los incapaces propiamente dichos, sino porque se parte del supuesto de que es incierta su existencia y el de que todos ignoran el sitio en que se halla. (...) Declarada así la ausencia, el ausente es estimado un incapaz". (37)

León Barandiarán la critica en los siguientes términos:

"Es ésta una disposición que puede ser calificada de exótica (...) Sólo se trata de una situación especial: el ausente por el hecho de estar en tal situación, no puede ejercitar por sí mismo los actos de la vida civil, y hay que proveerlo de un representante legal" (38).

En nuestra opinión, en este artículo se comete dos errores. En primer lugar, hacer referencia a la ausencia declarada, situación que no está regulada por el Código. En segundo lugar, señalar como

(37) RODRIGUEz LleRENA, Darío. Código Civil. Chiclayo, Librería e Imprenta Mendoza. 1937. Tomo I. P. 460.

(38) LEON BARANDIARAN, José. Manual de Derecho Civil. Derecho de las Personas. Lima. Universidad Nacional Mayor de San Marcos. P. 45. 
incapaz absoluto al declarado ausente, lo cual, como ya hemos expuesto, es un error.

\section{CAPITULO III: CODIGO CIVIL DE 1984}

El Código Civil peruano de 1984 en el Libro I, Título VI, divide la ausencia en dos etapas: desaparición y declaración de ausencia. Tal como lo hemos mencionado anteriormente, Fernández Sessarego afirma que se trata de una innovación sistemática en nuestra normatividad civil (39), y que "el Título Sexto responde, en alguna medida, a una inspiración nativa", si bien reconoce la influencia principal de los códigos italiano de 1942 y portugués de 1967, así como del Anteproyecto del Código brasileño de 1963 (40).

1. Desaparición.-

\subsection{Elementos configurativos}

La situación de desaparición se configura (art. 47):

a. Cuando una persona no se halla en el lugar de su domicilio.

(39) Cabe observar, sin embargo, que la terminologia reiativa a la ausencia que se emplea a través del articulado del Código vigente no es coherente con la sistemática adoptada al regular esta institución. Así, puesto que el TYtulo VI del Libro I se denomina "Ausencia" y su primer capítulo "Desaparición", debe interpretarse que el término "ausencia" es el género y "desaparición" la especie. No obstante, en el mismo Título VI puede apreciarse que se emplea el término "desaparecido" como genérico (arts. 49, 63, 64 y 65). Asimismo, se emplean los términos "ausencia", "ausente" y "desaparecido" muchas veces como equivalentes, dando lugar a confusión, como luego se verá al revisar los efectos de la ausencia en la esfera familiar. Véase igualmente los artículos $334,364,637,987,1307,1651$, entre otros.

(40) FERNANDEZ SESSAREGO, Carlos. Derecho de las... Ob.Cit. P. 115. 
b. Se carece de noticias sobre su paradero.

c. No existe mandatario con facultades suficientes. La redacción del Código, de usar el término "mandatario" en vez de "representante" o "apoderado", no es la más conveniente.

\subsection{Titularidad de la acción y competencia}

Están facultados para solicitar el nombramiento de curador de bienes para el desaparecido, la parte interesada o el Ministerio Público (art. 47).

En virtud de lo dispuesto en el artículo VI del Título Preliminar, cualquier persona que tenga legítimo interés podrá solicitar el nombramiento de curador. También podrá hacerlo el Ministerio Público en razón de representar el interés social (ya que la desaparición afecta no solamente a los familiares del desaparecido sino a la comunidad en general).

Sobre la competencia jurisdiccional podría crearse problemas de interpretación, puesto que según el artículo 47 sería competente al juez del lugar donde se encuentren "sus bienes" y según el artículo 609 el del lugar donde se hallen "todos o la mayor parte de sus bienes". Creemos que el art. 601 no debió hacer referencia a la competencia (por estar ya regulada) y coincidimos con Cornejo Chávez respecto de la aplicación del art. 47 , por ser específico sobre la materia y a la vez tener mayor amplitud (41).

\subsection{Efectos patrimoniales: curatela de bienes}

El efecto de la desaparición es la designación judicial de un curador de bienes para el desaparecido (arts. 47 y 597).

El ejercicio del cargo de curador tiene carácter interino y corresponde que lo ejerzan (art. 597), en primer lugar, las personas

(41) CORNEJO CHAVEZ, Héctor. Derecho Familiar Peruano. Lima. Studium S.A. 5ta. Ed. 1985. Tomo II. P. 442. 
llamadas a la curatela legitima (art. 569); en segundo lugar, a falta de curador legítimo corresponderá el cargo al curador nombrado por testamento o por escritura pública (art. 572); de no existir ninguno de los anteriores, será designado por el consejo de familia (art. 573), y de no ser ello posible, lo nombrará el juez (art. 597).

En principio, las facultades del curador del desaparecido son: a) la custodia y con servación de los bienes; b) el cobro de créditos y el pago de las deudas; $y, c)$ la representación en juicio del desaparecido.

Como excepción a este principio, los actos prohibidos para el curador pueden ser válidos cuando, probada la necesidad o utilidad, son autorizados por el Juez con la previa audiencia del Consejo de Familia (art. 602). Adicionalmente, el Juez señalará al curador sus facultades y obligaciones, según las circunstancias (art. 605), lo cual es acertado, puesto que las relaciones jurídico-patrimoniales del desaparecido pueden requerir de facultades mayores que las conferidas como regla general, $y$, en consecuencia, esta norma permite una mejor protección de los bienes del desaparecido.

Cabe hacer notar que el artículo 597 incurre en el mismo error advertido en el Código de 1936 (artículo 590), cuando trata como equivalentes los términos "ausencia” y "desaparición”. En este artículo ha debido omitirse la mención a la ausencia (puesto que regula la curatela del desaparecido).

Dicha curatela cesa, según el art. 616, por el retorno del desaparecido y al declarársele ausente o muerto presunto. Se ha omitido mencionar expresamente dos supuestos obvios: su muerte real y el hecho que designe representante con facultades suficientes con posterioridad al nombramiento del curador.

La resolución que nombra curador de bienes al desaparecido se inscribe en el Registro Personal, (artículo 2030, inciso 2). Incurre en error el legislador al expresar "... resoluciones que declaren la desaparición...", ya que esta es una situación de hecho y lo que existe es una resolución designando un curador interino (42).

(42) En esta crítica coincidimos con Fernández Sessarego, quien expresa 


\subsection{Efectos con relación a la familia}

Los efectos de la desaparición en la esfera familiar son los siguientes:

a) En lo referente a la invalidez del matrimonio, se establece que en caso que el cónyuge de un desaparecido contrajera nuevo matrimonio, esta nueva unión sólo puede ser impugnada por el nuevo cónyuge, mientras dure la ausencia y no se declare la muerte presunta, y siempre que hubiere procedido de buena fe (art. 274 , inc. $3^{\circ}$ ). Sobre éste punto trataremos con mayor detalle al analizar los efectos de la declaración de ausencia en relación con la familia.

b) Las facultades de dirección, representación y administración de la sociedad conyugal las asume uno de los cónyuges cuando "se ignora el paradero del otro" o éste se encuentra en lugar remoto (arts. 294 , inc. $2^{\circ}$, y 314 ). Al mencionarse la ig-

que la Comisión Reformadora no previó un Libro sobre Registros Públicos, de allí que exista contradicción entre este artículo y el artículo 47. Véase: FERNANDEZ SESSAREGO, Carlos. La Desaparición. en el nuevo Código Civil de 1984. En: Pontificia Universidad Católica del Perú. Para leer el Código Civil. Lima, 1985, publicado como Apéndice en Derecho de las... pags. 272-273. Crítica que se reitera en: FERNANDEZ SESSAREGO, Carlos y CARDENAS QUIROS, Carlos. Estudio Preliminar Comparativo de algunos aspectos del Código Civil Peruano de 1984 en relación con el Código Civil Italiano de 1942. En: El Código Civil Peruano y el Sistema Jurídico Latinoamericano. Lima. Cultural Cuzco, 1986. Pags. 115, 116 y 147. La Comisión Revisora, según la Exposición de Motivos del Libro IX del Código Civil, elaborada por Jack Bigio Chrem y Victor Raúl Ramírez, admite la posibilidad del cuestionamiento en lo que se refiere a la resolución de la desaparición, pero justifica el texto tal como está redactado en vista que el nombramiento del curador "resulta siendo, aunque el artículo 47 no lo señale, una declaración tácita de la desaparición, por cuanto si esta última no se produjera como tal carecería de objeto la designación de curador interino". Comisión Revisora del Código Civil. Exposición de Motivos Oficiales del Código Civil. En: Diario Oficial El Peruano. Lima, 19 de julio de 1987. Separata especial, p. 29. 
norancia del paradero se alude tácitamente a la desaparición (en virtud de lo previsto en el artículo 47). Aunque el código no lo señala expresamente, se entiende que esta situación es provisional y debe cesar del mismo modo en que cesa la curatela del desaparecido.

c) Respecto a la unión de hecho, el código establece que ésta termina por "ausencia". En vista que bajo el título de ausencia se regulan tanto la desaparición cuanto la declaración de ausencia, podría afirmarse que la unión de hecho termina por la desaparición de uno de los concubinos. Sin embargo, dado que de lo que se trata es de proteger el patrimonio del desaparecido ante su desaparición imprevista, no creemos que afecte su status personal, y por ende, que sea causa de término de la unión de hecho. Consideramos más bien que aquí el término "ausencia" está referido a la declaración de ausencia.

d) La desaparición del marido es causa de negación de la paternidad matrimonial (art. 363 , inc. 2 do.), en tanto que implica una imposibilidad manifiesta de cohabitación (43).

e) En cuanto a la acción de separación de cuerpos, se señala que ésta corresponde a los cónyuges, pero los ascendientes pueden accionar si alguno "es incapaz, por enfermedad mental o ausencia" (art. 334). (Cabe apreciar la errónea consideración del ausente como incapaz) (44).

En tal virtud, la desaparición de uno de los cónyuges faculta a los ascendientes a interponer la acción de separación de cuerpos.

(43) CORNEJO CHAVEZ, Héctor. Ob.Cit. T. II. P. 38.

(44) La redacción de esta norma no es acertada, pues se está entendiendo a la ausencia como causal de incapacidad, lo que no guarda coherencia con la concepción de ausencia contenida en la parte pertinente del Código Civil vigente. Como ya hemos observado al referirnos a los antecedentes en nuestra legislación sobre la ausencia, su inclusión entre las causales de incapacidad constituyó una notoria inexactitud del Código Civil de 1936. 
f) En lo relativo a la Patria Potestad, ésta se suspende cuando se comprueba que el padre o la madre se hallan "impedidos de hecho para ejercerla" (art. 466). Por tanto, se suspende por la desaparición de alguno de ellos.

\section{Declaración de ausencia}

\subsection{Elementos configurativos}

Los elementos que configuran la declaración de ausencia (art. 49) son: 1. El hecho de la desaparición; 2. El transcurso de dos años desde las últimas noticias; y 3 . La resolución judicial.

El segundo elemento caracteriza a esta figura jurídica. El transcurso del tiempo da lugar a que, al no reaparecer la persona desaparecida, se llegue a tener una incertidumbre respecto de su existencia.

El Código no establece un plazo mayor para la declaración de ausencia cuando el desaparecido tiene apoderado con facultades suficientes. Consideramos que este caso debió contemplarse puesto que los intereses del desaparecido están debidamente protegidos y puede presumirse que el sujeto previó su alejamiento (45).

En concordancia con la posición de que procede declarar la ausencia aunque exista apoderado facultado del ausente, se establece la inscripción de la declaración de ausencia en el registro de mandatos y poderes para extinguir los otorgados por el ausente (art. 53).

(45) Al respecto, el Code establece que si el ausente ha dejado poder, los presuntos herederos no podrán pedir la declaración de ausencia sino transcurridos diez años desde la desaparición de aquél o después de sus últimas noticias (artículo 121); siendo necesario, para el supuesto del ausente sin apoderado que lo represente, el transcurso de cuatro años (artículo 115). 
Están legitimados para solicitar la declaración de ausencia (art. 49), en primer lugar, cualquiera que tenga legítimo interés (conforme el artículo VI del Título Preliminar), y el Ministerio Público (por existir un interés social).

El juez competente es el del último domicilio que tuvo el desaparecido o el del lugar donde se encuentre "la mayor parte de sus bienes" (art. 49).

Como puede apreciarse, se ha adoptado un criterio distinto al previsto para el caso de desaparición, que se refiere - como ya hemos señalado-, al juez del "lugar donde se encuentren sus bienes". Si bien ambas etapas son independientes, por cuanto no se requiere que se haya nombrado curador al desaparecido para declarar la ausencia, creemos debió seguirse un mismo criterio en ambas situaciones para determinar la competencia jurisdiccional.

\subsection{Efectos patrimoniales: posesión temporal de bienes}

El efecto de la declaración por ausencia, con relación al patrimonio, es el de dar la posesión temporal de los bienes del ausente a quienes serían sus herederos forzosos en el momento de la declaración (art. 50): es decir, a sus descendientes, ascendientes o cónyuge (art. 724) (46).

En caso de que el declarado ausente no tuviera herederos forzosos, "continuará" la curatela establecida en el artículo 47 (art. 50 in fine). En concordancia con Javier de Belaunde consideramos que el empleo del término "continuará" no es acertado, por cuanto

(46) Según el ponente, se ha señalado a los herederos forzosos porque: "El Código contempla el interés de aquellos que forman el núcleo íntimo de la familia, es decir de los que presumiblemente han dependido económicamente del ausente y que, en cierta manera, han coparticipado de la posesión de sus bienes". FERNANDEZ SESSAREGO, Carlos, Ob.Cit. P. 1129 . 
sugiere que el nombramiento de curador del desaparecido es necesario para la declaración de ausencia (47).

Entendemos que, de no existir herederos forzosos del declarado ausente, deberá continuarse con la curatela establecida por el artículo 47, siempre que se hubiera nombrado curador. De no ser así, se declarará la ausencia y deberá nombrarse un curador como en el caso de la desaparición.

Es conveniente destacar el criterió seguido por el Código, según el cual la declaración de ausencia no origina la apertura de los actos de última voluntad del ausente (48). Consideramos que este criterio es acertado, pues durante la declaración de ausencia, pese a crearse ya una incertidumbre sobre la existencia del ausente, se debe presumir la vida de éste hasta que se compruebe su muerte o sea declarada judicialmente. Coincidimos con la opinión de Lanatta, ya que no se justifica que la declaración de ausencia "ponga en funcionamiento prematuramente el mecanismo sucesorio" (49).

En cuanto a los derechos sucesorios del declarado ausente, puesto que de acuerdo a nuestro Código Civil el ausente no es considerado un incapaz, Augusto Ferrero Costa dice que al "no haberse declarado su muerte (sólo es ausente), puede recoger bienes hereditarios" (50).

(47) DE BELAUNDE, Javier. Desaparición, Ausencia y Muerte Presunta, Tres años después. En: Themis. Revista de Derecho. Pontificia Universidad Católica del Perú. Segunda Epoca, 1988. № 10, P. 67.

(48) Contraria es la posición del Código italiano (artículo 50), que dispone la apertura de los actos de última voluntad del ausente, si existen, al quedar ejecutable la sentencia que declara la ausencia. Este último criterio está contenido asimismo en el Código de Portugal (artículos 100 a 103), y también en el Código de Brasil, en lo que denomina la "sucesión provisoria".

(49) LANATTA, Rómulo. Ob.Cit. P. 162.

(50) FERRERO, Augusto. El Derecho de Sucesiones en el nuevo Código Civil peruano. Lima. Fundación M.J. Bustamante De la Fuente. 1987, P. 45. 
La terminación de la situación de ausencia declarada se produce por las siguientes causales (art. 59): 1. Regreso del ausente. 2. Designación de apoderado con facultades suficientes, hecha por el ausente con posterioridad a la declaración. 3. Comprobación de la muerte. 4. Declaración judicial de muerte presunta.

Las consecuencias jurídicas originadas por las causales de cese son dos (art. 60):

1. La restitución de su patrimonio al ausente, si es que regresa o designa apoderado suficiente con posterioridad a la declaración.

2. La apertura de sucesión, si se comprueba su muerte o se declara su muerte presunta.

Por razones de sistemática (51) habría sido mejor ubicar la referencia a la apertura de la sucesión en el título VII del Libro I (Declaración de Muerte Presunta), que es donde corresponde.

\subsection{Efectos en relación con la familia}

\section{a) Invalidez del matrimonio}

El Código Civil señala que es nulo el matrimonio del casado (artículo 274, inciso tercero). Establece, sin embargo, que si el primer cónyuge ha muerto o si el primer matrimonio ha sido invalidado o disuelto por divorcio, sólo el segundo cónyuge del bígamo puede demandar la invalidación, siempre que haya actuado de buena fe y dentro del plazo de un año contado a partir del día en que tuvo conocimiento del matrimonio anterior.

"Tratándose del nuevo matrimonio contraido por el cónyuge de un desaparecido - dice el Código en el párrafo que nos interesa comentar - sin que se hubiera declarado la muerte presunta de éste, sólo puede ser impugnado, mientras dure el estado de

(51) SOLARI AGUELA, Giancarlo. Causas y Efectos de la Apertura de Sucesión. Tesis de Bachiller. Lima. Pontificia Universidad Católica del Perú. 1987. P. 245. 
ausencia, por el nuevo cónyuge y siempre que hubiera procedido de buena fe".

En nuestra opinión, la norma no tiene un texto claro por cuanto, por un lado, hace mención al cónyuge del "desaparecido", y por otro, establece que la impugnación sólo cabe "mientras dure el estado de ausencia". Esta redacción puede originar problemas de interpretación por cuanto la expresión "estado de ausencia" puede ser entendida como comprendiendo tanto a la desaparición cuanto a la ausencia declarada (dada la denominación genérica del Título VI del Libro I), o sólo como ausencia declarada (si se considera que la naturaleza de ésta es la de estado civil). En esta última hipótesis, tratándose de un desaparecido al que no se ha declarado ausente, no podría plantearse la nulidad del matrimonio, pues aún no hay estado de ausencia, lo cual implicaría que sería necesario esperar por lo menos dos años para plantear la acción de invalidez.

Consideramos que, en el inciso tercero del artículo 274 , los términos "desaparición" y "estado de ausencia" se refieren a la ausencia en general; es decir, que el segundo cónyuge puede impugnar el nuevo matrimonio tratándose de desaparición o de declaración de ausencia.

Creemos, pues, que la intención del legislador de 1984, en el párrafo que es objeto de nuestro análisis, ha sido proteger al nuevo cónyuge de buena fe, otorgándole el derecho de proceder a la impugnación mientras no se haya producido el retorno del desaparecido o del declarado ausente y no se haya declarado su muerte presunta.

b) Dirección, representación y administración de la sociedad conyugal

Como veremos, al declararse la ausencia la sociedad de gananciales fenece (art. 318 , inc. 4to.) y, en consecuencia, no habrá bienes comunes que administrar, pasando los bienes propios del cónyuge declarado ausente en posesión temporal a los presuntos herederos de éste (arts. 50 y 51). Por consiguiente, al cónyuge presente únicamente le corresponderá la administración de los bienes propios de su cónyuge ausente, en el supuesto de ser único heredero forzoso. 


\section{c) Sociedad de gananciales}

La declaración de ausencia está considerada (art. 318 , inciso 4 to.) como causal de fenecimiento del régimen de sociedad de gananciales.

Fenecida por esta causal la sociedad de bienes, y practicada su liquidación, "el cónyuge presente asumirá el manejo de los bienes que le hayan sido adjudicados con las mismas características de un régimen de separación de patrimonios en tanto que la parte correspondiente al ausente será entregada en posesión temporal a quienes serían sus herederos forzosos" (52).

El momento en que se considera fenecido el régimen de sociedad de gananciales es regulado en dos niveles por el artículo 319 del código vigente.

En un primer nivel, respecto a la relación entre los cónyuges, la sociedád de gananciales se considera fenecida en la fecha de la declaración de ausencia. En un segundo nivel, respecto a terceros, se considera fenecido dicho régimen en la fecha de la inscripción de la declaración de ausencia en el Registro Personal.

Es importante destacar la innovación contenida en el tercer párrafo del artículo 323 , en el que se establece que al fenecer la sociedad de gananciales por declaración de ausencia de uno de los cónyuges, el cónyuge presente tiene derecho preferencial para la adjudicación de la casa en que habita la familia, y del establecimiento agrícola, artesanal, industrial o comercial de carácter familiar.

Esta norma es concordante con el artículo 731 del Código Civil vigente, que concede al cónyuge sobreviviente el derecho de habitación vitalicio y gratuito sobre la casa en que existió el hogar conyugal.

(52) CORNEJO CHAVEZ, Héctor. Ob.Cit. T.I, p. 310. 


\section{d) Separación de patrimonios}

Al declararse la ausencia, los bienes propios del cónyuge declarado ausente pasarán en posesión temporal a sus presuntos herederos forzosos (art. 50), entre los cuales está el cónyuge presente.

\section{e) Decaimiento y disolución del vínculo matrimonial}

Nos parece importante comentar el artículo 334 relativo a la acción de separación de cuerpos. En este artículo se señala que la acción de separación corresponde, por regla general, a los cónyuges. Sin embargo, en forma excepcional se faculta para accionar a los ascendientes si alguno de los cónyuges "es incapaz, por enfermedad mental o ausencia".

Como ya hemos observado al referirnos a los antecedentes en nuestra legislación sobre la ausencia, su inclusión entre las causales de incapacidad constituyó una notoria inexactitud del Código de 1936.

En cuanto al sentido en que debe interpretarse el término "ausencia" en este artículo, consideramos que se refiere tanto a la desaparición cuanto a la declaración de ausencia.

\section{f) Unión de hecho}

El Código vigente regula lo concerniente a la unión de hecho en el artículo 326. En su tercer párrafo señala como una de las causas de su terminación a la "ausencia".

El empleo del término "ausencia", como ya lo hemos expresado, puede referirse tanto a la desaparición cuanto a la declaración de ausencia. Podría considerarse que, no habiendo distinguido el legislador, debe interpretarse que la unión de hecho termina al producirse cualesquiera de ellas.

Ahora bien, cabe hacer notar que, como ya expresáramos, la curatela de bienes del desaparecido tiene lugar ante una emergencia, cual es que los bienes de una persona desaparecida 
queden abandonados, siendo la designación del curador la consecuencia jurídica de la desaparición. Así, esta situación que tiene carácter provisional o transitorio, no afecta el status personal del desaparecido y, en consecuencia, no puede producir el fin de la unión de hecho.

Debe tenerse presente que, de existir bienes que cautelar, podria solicitarse el nombramiento de curador con el exclusivo fin de proveer al cuidado de tales bienes y no con la voluntad de poner fin al concubinato, de modo que al retornar el desaparecido sería necesario que transcurrieran nuevamente dos años para que se constituya la sociedad de bienes.

Un argumento que podría esgrimirse para afirmar que con la desaparición de uno de los concubinos termina la unión de hecho, es que tratándose ésta de una situación de convivencia habitual o posesión continua de estado, al no encontrarse alguno de los concubinos la unión de hecho debe llegar a su fin.

En consecuencia, tratándose de la causal de ausencia a la que alude el Código, consideramos que sería excesivo poner fin a la unión de hecho con la sola desaparición; más bien, el término ausencia al que se refiere el artículo 326 , debe ser entendido en sentido restrictivo, esto es, como declaración de ausencia, pues el transcurso de dos años es un plazo prudencial para poner fin a la unión de hecho, y por tanto, a la sociedad de bienes correspondiente.

En cuanto al momento en que debe tenerse por disuelta la sociedad de bienes derivada de la unión de hecho, coincidimos con Cornejo Chávez, quien, al referirse a las normas de la sociedad de gananciales aplicables a la sociedad de bienes (primer párrafo del art. 326), considera que para determinar la fecha de fenecimiento de esta última es aplicable el artículo 319 (que señala el fenecimiento en la fecha de la declaración de ausencia) (53).

\section{g) Filiación}

Como ya mencionáramos, el inciso segundo del artículo 363 faculta al marido a negar la paternidad del hijo de su mujer

(53) CORNEJO CHAVEZ, Héctor. Ob.Cit. T. I. P. 315. 
cuando sea manifiestamente imposible, dadas las circunstancias, que haya cohabitado con ésta en los primeros 121 días de los 300 anteriores al nacimiento del hijo.

Cornejo Chávez considera, dentro de las circunstancias de imposibilidad manifiesta de cohabitación, a la ausencia (54). Coincidimos con esta apreciación y entendemos que el término "ausencia" debe interpretarse en forma genérica, es decir, que comprende a la desaparición y a la declaración de ausencia (e inclusive como falta de presencia).

El artículo 364, relativo al plazo para interponer la acción contestatoria de paternidad, señala que éste es de 90 días y se cuenta desde el día siguiente del regreso del marido, si estuvo "ausente".

En cuanto a la filiación extramatrimonial, en tanto que para ella se requiere del reconocimiento del padre o de la sentencia declaratoria de la paternidad (art. 387), en este último caso no prosperará la acción de declaración judicial de filiación extramatrimonial si el presunto padre se hubiera encontrado desaparecido o declarado ausente durante la época de la concepción, pues no habría sido posible que éste hiciera vida en común con la madre (art. 402 inciso tercero) (55).

\section{h) Patria potestad}

El artículo 466 en su inciso tercero prescribe que la patria potestad se suspende "cuando se comprueba que el padre o la madre se hallan impedidos de hecho para ejercerla"; en consecuencia, la declaración de ausencia es un supuesto por el que el ejercicio de aquella se suspende.

(54) CORNEJO CHȦVEZ, Héctor. Ob.Cit. T. II, p. 38.

(55) Respecto a la Declaración Judicial de Paternidad Extramatrimonial, véase: CORNEJO CHAVEZ, Héctor. La Declaración Judicial de la Paternidad Extramatrimonial. En: Libro Homenaje a José León Barandiarán. Cultural Cuzco S.A. Lima, 1985. Pp. 59 a 74. 


\section{i) Consejo de familia}

En la parte relativa al Consejo de Familia, encontramos que los artículos $637,638,653$ y 654 están vinculados a la ausencia.

El art. 637 señala a la "ausencia sin dejar apoderado" como uno de los casos en los que, por no quedar cuatro miembros hábiles, el número de miembros del consejo de familia debe completarse.

Creemos que esta norma debe referirse tanto a la desaparición cuanto a la declaración de ausencia, dado que en esta última etapa, aun cuando existiera apoderado nombrado, de acuerdo al Art. 53 la inscripción en el Registro de Mandatos y Poderes de la resolución que declara la ausencia extingue los otorgados por el ausente.

El artículo 638 establece que el consejo se forma para que ejerza sus atribuciones en favor de los "ausentes".

Consideramos que en este artículo el término "ausentes" únicamente tendrá efectos respecto a la situación de desaparición, específicamente sobre la curatela de bienes del desaparecido, siendo irrelevante en lo que se refiere a la declaración de ausencia.

\section{Muerte presunta}

El Código Civil de 1984 regula la declaración de muerte presunta independientemente de la ausencia, en el Título VII del Libro I denominado "Fin de la persona", conjuntamente con la muerte natural. Constituye una de las innovaciones del nuevo Código a nivel de la legislación comparada.

\subsection{Elementos configurativos}

Los elementos configurativos de la declaración de muerte presunta son los siguientes: 
1. "Cuando hayan transcurrido diez años desde las últimas noticias del desaparecido o cinco si éste tuviere más de ochenta años de edad" (art. 63, inc. 1ro.).

Este supuesto está referido al hecho de la desaparición prolongada de una persona. Se establece un plazo abreviado de cinco años desde las últimas noticias del desaparecido cuando éste tuviere más de ochenta años de edad, lo cual se justifica en opinión de Fernández Sessarego "en tanto que no es infrecuente que la desaparición ocurra en edad muy próxima a los ochenta años 0 , simplemente, con posterioridad al cumplimiento de tal hecho" (56).

El Código no señala expresamente desde qué fecha se deben considerar las últimas noticias del desaparecido para efectos del cómputo de los plazos. Cabrian dos interpretaciones: tomar como fecha de las últimas noticias la de la emisión de éstas, o tomar como fecha la de su recepción.

Consideramos que debe entenderse como fecha de las últimas noticias la de la emisión de éstas, puesto que hasta esa fecha se tiene la certeza de que el desaparecido está con vida, lo cual no ocurre de tomarse como fecha la de la recepción, ya que en el lapso entre la emisión y la recepción no es posible determinar hasta qué momento el desaparecido se encontraba con vida (57).

2. "Cuando hayan transcurrido dos años si la desaparición se produjo en circunstancias constitutivas de peligro de muerte. El plazo corre a partir de la cesación del evento peligroso" (art. 63, inc. 2do.).

Este inciso está referido al supuesto en que la desaparición de una persona haya ocurrido en circunstancias de peligro de tal naturaleza que lleven a presumir la muerte de ésta, razón por la cual el plazo establecido por la ley es de sólo dos años.

(56) FERNANDEZ SESSAREGO, Carlos. Derecho de las Personas. Librería Studium. Lima, 1988. P. 133.

(57) SOLARI AGUELA, Jorge Giancarlo. Ob.Cit. Pp. 240-241. 
Dentro de este supuesto se inscriben eventos como guerras, terremotos, incendios, naufragios y otros accidentes similares, que en el derecho alemán (arts. 15 a 17) constituyen los supuestos de hecho de la denominada "ausencia calificada" (58).

3. "Cuando existe certeza de la muerte, sin que el cadáver sea encontrado o reconocido" (art. 63, inc. 3ro.).

Este supuesto está referido a los casos en que, por diversas circunstancias, puede afirmarse que una persona ha fallecido, pero no puede extenderse el certificado de defunción, ya sea porque no se encontró el cadáver o porque éste no pudo ser reconocido.

Cabe mencionar que la declaración de ausencia no es requisito para que proceda la declaración de muerte presunta (art. 63, primer párrafo).

\subsection{Titularidad de la acción y competencia}

Están legitimados para pedir la declaración de muerte presunta de una persona, en primer lugar, cualquier interesado y, en segundo lugar, el Ministerio Público (art. 63, primer párrafo).

La expresión "cualquier interesado", concordada con lo dispuesto por el artículo VI del Título Preliminar, implica que la acción puede ser ejercitada por quienes tengan legítimo interés económico o moral.

La norma concede asimismo el ejercicio de la acción al Ministerio Público (al igual que para pedir el nombramiento de curador de bienes para el desaparecido y para solicitar la declaración de ausencia). En el caso particular de la declaración de muerte presunta, creemos que la intervención del Ministerio Público para ejerci-

(58) ENNECCERUS, Kipp y Wolf. Tratado de Derecho Civil. Barcelona. Bosch, 1955. T. I. Vol. I. P. 331. 
tar la acción está justificada en el deber de representar a la sociedad en juicio y en el de defender el interés social (art. 250, inciso tercero de la Constitución, y art. 1ro. del Decreto Legislativo No. 52), en tanto que a la sociedad interesa que no existan en forma indefinida situaciones jurídicas de incertidumbre con relación a la familia y al patrimonio de una persona.

El Código Civil, a diferencia de los casos de desaparición y de declaración de ausencia, no regula lo concerniente al Juez competente para declarar la muerte presunta. Sin embargo, tal regulación la podemos encontrar en las normas procesales aplicables.

De acuerdo al inciso primero del artículo 7 del D.Leg. 310 , la tramitación de la declaración de muerte presunta se rige por lo dispuesto en los artículos 1284 a 1287 del Código de Procedimientos Civiles, en cuanto fueren aplicables, normas que regulan la "posesión de los bienes del ausente".

El artículo 1285 del Código adjetivo, para efectos de la sustanciación de la solicitud, remite a las normas relativas a la guarda de los bienes del ausente (arts. 1272 a 1283 del C. de P.C.). Dentro de estas normas, el artículo 1274 señala como juez competente al del último domicilio o residencia del ausente, o el de aquél en que se encuentren sus bienes.

3.3 Momento en que surte efecto la resolución que declara la muerte presunta

Un aspecto de suma importancia para entrar al análisis de los efectos de la declaración de muerte presunta, es el de precisar desde cuándo rigen los efectos de la resolución respectiva. $\mathrm{Ni}$ el Código Civil ni el Código de Procedimientos Civiles se refieren a este punto expresamente, por lo que debe atenderse al tipo de sentencia que declara la muerte presunta.

Una de las clasificaciones de las sentencias es aquella que las divide según sus efectos en constitutivas y declarativas.

La sentencia constitutiva crea una situación jurídica 
hasta entonces inexistente, o modifica o extingue la situación jurídica que ya existía, de modo que sus efectos se proyectan hacia el futuro, ya que la nueva situación nace de la propia sentencia.

La sentencia declarativa, por su parte, tiene por objeto la mera declaración sobre una situación de hecho o de derecho, sin llegar a producir efecto constitutivo; la sentencia no crea nada sino que reconoce algo preexistente, por lo que sus efectos se retrotraen al momento de producirse la situación de hecho o de derecho que declara.

La resolución que declara la muerte presunta debe indicar la fecha probable y, de ser posible, el lugar de la muerte del desaparecido (art. 65). El sentido de esta norma es determinar el momento que debe tomarse como punto de partida para los efectos de la declaración judicial de muerte presunta, pues como bien dice Fernández Arce:

"La resolución judicial no hace sino dar alcance jurídico al hecho presunto declarado, de modo que sus efectos se retrotraen al momento de esa fecha probable" (59).

Así pues, podemos afirmar que en el caso de la declaración judicial de muerte presunta, estamos ante una sentencia de tipo declarativo, cuyos efectos rigen no desde que se dicta sino que se retrotraen a la fecha que se señala en dicha resolución como aquella en que se produjo la muerte.

\subsection{Efectos de la declaración de muerte presunta}

El efecto fundamental de la resolución que declara la muerte presunta es poner fin a la persona. Aunque el Código Civil no lo diga expresamente, ello se deduce de la ubicación de las normas

(59) FERNANDEZ ARCE, César. Las Acciones Reales en el Derecho Sucesorio. En: Libro Homenaje a Rómulo Lanatta Guilhem. Lima. Cultural Cuzco S.A. 1986. Pp. 189-190. 
que la regulan (conjuntamente con la muerte comprobada, dentro del Título "Fin de la Persona").

En tal sentido, sus efectos jurídicos serán los mismos que los derivados de la muerte comprobada. Esta ha sido la posición que nuestro Código ha adoptado.

\subsection{Efectos patrimoniales}

En la esfera patrimonial, el efecto más importante es dar lugar a la apertura de sucesión de la persona declarada muerta presuntamente (Art. 60 in fine) (60).

La resolución que declara la muerte presunta - como ya hemos expresado-, debe indicar la fecha probable $y$, de ser posible, el lugar de la muerte (Art. 65), ya que como bien observa Fernández Sessarego:

"La fijación de una probable fecha, en la situación prevista, permite conocer el instante a partir del cual se origina la transmisión sucesoria y sus efectos consiguientes" (61).

Así pues, los efectos de la resolución que declara la muerte presunta se retrotraen a la fecha indicada en ella como de la muerte probable, la cual marcará el momento de apertura de sucesión.

Otro efecto de contenido patrimonial es el de dar lugar al cese de la curatela de bienes del desaparecido, de haberse nombrado

(60) Aunque constituye un acierto del Código establecer de manera clara que en virtud de la declaración de muerte presunta se produce la apertura de sucesión, esta norma debió estar ubicada dentro del capítulo de la declaración de muerte presunta y no en el de la declaración de ausencia, para conservar la sistemática del Código. SOLARI AGUELA, J. Giancarlo. P. 245.

(70) FERNANDEZ SESSAREGO, Carlos. Derechos de las .... P. 135. 
curador (art. 616). Del mismo modo, en su caso, hará cesar los efectos de la declaración de ausencia (art. 59 inciso 4o.).

Un aspecto importante que merece destacarse es el referido a la escisión que se produce en el patrimonio del presunto muerto en el supuesto de que éste se encontrara con vida en otro lugar, en el cual pudiera haber constituido un patrimonio personal distinto al que dejó en el lugar donde no se encuentra y en el que se le presume muerto. Ello se debe al hecho de que la declaración de muerte presunta, si bien determina una situación jurídica en el círculo sociojurídico donde se le considera muerto, no afecta la situación jurídica que pudiera tener en una esfera ajena e ignorada en la anterior.

\subsection{Efectos en relación con la familia}

\section{a) Matrimonio}

La declaración de muerte presunta disuelve el matrimonio del desaparecido (art. 64). Ello significa que el cónyuge presente queda facultado plenamente para contraer nuevo matrimonio.

Como puede observarse, esta norma es coherente con el criterio asumido por el Código, según el cual la declaración de muerte presunta produce los mismos efectos que la muerte comprobada.

El Código no señala expresamente en qué fecha se tiene por disuelto el vínculo matrimonial. Sin embargo, de acuerdo a lo expresado con relación a los efectos de la sentencia que declara la muerte presunta, la disolución del vínculo matrimonial se producirá en la fecha de la muerte probable, pues, como ya vimos, se trata de una sentencia declarativa cuyos efectos son retroactivos.

\section{b) Sociedad de gananciales}

Otro efecto importante es el relativo al fenecimiento de la sociedad de gananciales o comunidad de bienes. De ser éste el régimen vigente adoptado, fenece por la declaración de muerte presunta (art. 318, inciso quinto). 
Cabe precisar que este efecto no tiene lugar cuando la declaración de muerte presunta ha sido precedida de una declaración de ausencia, ya que en tal hipótesis ésta última habría determinado ya el fenecimiento de la sociedad de gananciales (art. 318 , inc. 4).

El Código contempla lo relativo a la fecha en la cual se tiene por fenecida la sociedad de gananciales, estableciendo que para las relaciones entre los cónyuges es la fecha de la declaración de muerte presunta (art. 319, primer párrafo). Empero, respecto de terceros, la fecha en que se considera fenecido el régimen de sociedad de gananciales será la fecha de inscripción de la sentencia en el registro personal, a fin de proteger a los terceros que realicen actos con la sociedad.

Sobre este tema, Cornejo Chávez expresa que "para las relaciones entre los mismo cónyuges, el fenecimiento se considera producido en la fecha de la muerte (real o presunta) ..." (62).

\section{c) Separación de patrimonios}

En forma similar a lo que ocurre en el régimen de sociedad de gananciales, el régimen de separación de patrimonios llegará a su fin con la declaración de muerte presunta, pues así lo preceptúa el artículo 331 que remite a lo dispuesto por el art. 318.

\section{d) Unión de hecho}

El Código señala como una de las causas por las que termina la unión de hecho, a la muerte (art. 326, tercer párrafo).

De acuerdo a lo anteriormente expuesto, al producir la declaración de muerte presunta los mismos efectos que la muerte comprobada, la unión de hecho y, por consiguiente, la socie-

(62) CORNEJO CHAVEZ, Héctor. Ob.Cit. Tomo I. P. 310. 
dad de bienes que ella origina, termina por la declaración de muerte presunta de alguno de los concubinos.

Respecto al momento en que debe considerarse terminada la unión de hecho, dado que la sociedad de bienes derivada de la unión de hecho debe sujetarse al régimen de sociedad de gananciales en cuanto le fuere aplicable (art. 326 primer párrafo), debe tomarse como fecha de terminación la de la declaración de muerte presunta.

\section{e) Aiinientos}

En cuanto a la obligación de prestar alimentos, dado que ésta se considera extinguida por la muerte del obligado (art. 486), se extinguirá igualmente por la declaración de muerte presunta.

Sin embargo, en el caso de existir algún hijo alimentista del declarado muerto, la porción disponible quedará gravada hasta donde fuera necesario para cumplir con el pago de la pensión respectiva (art. 728 ).

En el supuesto de que el presunto muerto fuera el alimentista, cesará asimismo el derecho de éste de recibir alimentos (art. 486).

Igualmente se extingue la pensión alimentaria que hubieren obtenido el cónyuge $u$ otros herederos forzosos (art. 58), ya que esta pensión supone aún la existencia del ausente y, al ser declarada su muerte presunta, ya no existe más el sujeto obligado a prestar la pensión alimentaria. Además, al producirse como efecto de la declaración de muerte presunta la transmisión sucesoria de los bienes, tanto el cónyuge cuanto los demás herederos forzosos ya no requieren de tal pensión, pues pasarán a ser propietarios en su porción respectiva de los bienes que fueron del causante.

\section{f) Patria potestad}

Respecto a los efectos de la declaración de muerte presunta con relación a la patria potestad, consideramos necesario distinguir algunos supuestos. 
En la hipótesis de que el presunto muerto sea un menor sujeto a la patria potestad, la patria potestad terminará, pues ella ya no es necesaria (art. 461 , inc. 1 ro.).

Distinto es el caso en el cual la declaración de muerte se produce respecto de una persona que ejerce la patria potestad. En esta hipótesis hay que distinguir dos situaciones.

Por un lado, cuando el presunto muerto ejerce la patria potestad en forma exclusiva y el otro padre ha muerto o es incapaz para ejercerla, la patria potestad termina definitivamente aun cuando el menor requiriera todavía del cuidado de una persona capaz, en cuyo caso se procederá al nombramiento de un tutor.

Por otro lado, en el supuesto de que uno de los padres fuera declarado presuntamente muerto $y$ el otro pudiera ejercer efectivamente la patria potestad, ésta subsiste; lo que se produce es el cese del ejercicio de la patria potestad por parte del presunto muerto.

\section{g) Tutela}

En la parte relativa a la tutela nos referiremos a dos situaciones: el fin de la tutela y el cese del cargo de tutor.

Respecto del fin de la tutela, una de las causas que ponen fin a esta institución es la muerte del menor (art. 549). Como ya hemos expuesto, al tener la declaración de muerte presunta los mismos efectos de la muerte comprobada, de ser declarada la muerte presunta de un menor sujeto a tutela, ésta llegará a su fin.

Una de las causas por las que se prevé el cese del cargo de tutor es la muerte del tutor (art. 550). En tal virtud, el cargo de tutor cesará al ser declarada la muerte presunta de quien lo ejerce, debiendo continuar los herederos del tutor con la gestión de su causante, si ellos son capaces, mientras se nombra al nuevo tutor (art. 551).

\section{h) Curatela}

El Código Civil no regula en forma específica 
la terminación de la curatela ni el cese del cargo de curador (art. 568), siendo de aplicación las normas ya comentadas relativas a la tutela (arts. 549, 550 y 551).

En consecuencia, la curatela terminará al ser declarada la muerte presunta de quien se encuentra sujeto a curatela y, asimismo, el cargo de curador cesará al ser declarada la muerte presunta de quien se encuentra ejerciendo dicho cargo.

Cabe mencionar que el Código contempla expresamente a la declaración de muerte presunta como causal de terminación de la curatela de bienes del desaparecido (art. 616).

\section{i) Consejo de familia}

En lo concerniente al consejo de familia, tienen relación con la declaración de muerte presunta los artículos 637 , 657 y 658 del Código Civil.

En caso de haberse declarado la muerte presunta de alguno de los miembros hábiles para asistir al consejo, el número de miembros deberá completarse según las reglas relativas a su formación (art. 637).

Uno de los casos en que se produce la terminación del cargo de miembro del consejo es por la muerte de éste (art. 657). Así, de ser declarada la muerte presunta de uno de los miembros del consejo de familia, éste cesará en el cargo.

Finalmente, el consejo de familia cesa en los mismos casos en que acaba la tutela o la curatela (art. 658). De modo que, remitiéndonos al artículo 549 que regula el fin de la tutela (y por remisión del artículo 568 también de la curatela), la declaración de muerte presunta del menor o del incapaz respecto del cual se ha formado el consejo de familia dará lugar a su terminación.

\section{Reconocimiento de existencia}

La declaración de muerte presunta está sustentada, como ya 
hemos expresado, en una presunción "iuris tantum", que puede ser enervada por el "Reconocimiento de Existencia", cuando se acredita la supervivencia de la persona cuya muerte presunta fue declarada (art. 67 del C.C.).

Están legitimados para solicitar dicho reconocimiento la persona que fue declarada presuntamente muerta, cualquier interesado y el Ministerio Público (art. 67).

El trámite es sumarísimo, pues se sigue en el mismo procedimiento de declaración de muerte presunta y no hay más requisitos que la citación a quienes intervinieron en este proceso y la prueba de la supervivencia.

Entendemos que tal prueba no se circunscribe a la presencia física de quien fue declarado. muerto sino a cualquier medio que permita establecer de manera indubitable que la susodicha persona se halla con vida.

Cabe acotar, asimismo, otro hecho que también destruye la presunción de muerte: la comprobación de muerte en fecha distinta a la indicada en la resolución que declara la muerte presunta (aspecto no contemplado expresamente en el Código).

La importancia de ello estriba en que pueden existir herederos distintos a quienes tenían tal calidad en la fecha declarada en la muerte presunta. De darse tal caso, quienes resultaran ser herederos a la muerte comprobada podrán ejercitar la acción petitoria de herencia (art. 664), la misma que es imprescriptible (63).

El efecto de reconocimiento de existencia en cuanto al patrimonio es facultar a la persona cuyo reconocimiento ha sido declarado para reivindicar sus bienes "conforme a ley" (artículo 69), expresión genérica que no establece en forma precisa los alcances de tal reivindicación.

(63) SOLARI AGUELA, Jorge G. Ob.Cit. Pp. 251 y 326. 
En la legislación comparada existen normas específicas que regulan con mayor claridad la reivindicación de bienes de aquél cuya existencia ha sido reconocida. Por ejemplo, las legislaciones civiles argentina (art. 32 de la Ley 14394), española (art. 197 del Código Civil) e italiana (art. 66 del Código Civil y Comercial), coinciden en establecer que los bienes se recuperan en el estado en que se encuentren y, además, que el reaparecido tiene derecho a obtener el precio de los bienes enajenados o los bienes adquiridos con aquél. El Código Civil español señala adicionalmente que el reaparecido "no podrá reclamar de sus sucesores los frutos, rentas o productos... sino desde el día de su presencia o de la declaración de no haber muerto" (art. 197).

De modo, pues, que sería más acertada la redacción del artículo 69 de nuestro Código Civil si se hubiera señalado en forma clara a qué bienes se extiende la reivindicación.

Sin embargo, para este efecto podrá aplicarse analógicamente el artículo 60, según el cual al cesar los efectos de la declaración de ausencia, se restituye a su titular el patrimonio en el estado en que se encuentre.

Los efectos más importantes del reconocimiento de existencia en relación con la familia son:

\section{a) Matrimonio}

El Código establece expresamente que el reconocimiento de existencia no invalida el nuevo matrimonio que hubiere contraido el cónyuge (art. 68).

Como puede apreciarse, se reafirma el carácter definitivo de la disolución del matrimonio derivada de la declaración de muerte presunta. Esta posición, incorporada al Código Civil por la Comisión Revisora, ha sido objeto de muchas críticas y de un intenso debate.

El Anteproyecto, según refiere Fernández Sessarego, tenía una posición contraria, pues disponía que al reconocerse la existencia del declarado presuntamente muerto el nuevo matrimonio que hubie- 
re contraido su cónyuge quedaba automáticamente nulo, aunque surtía los efectos del matrimonio nulo contraido de buena fe (64).

La Comisión Reformadora introdujo una variante al criterio del Anteproyecto en el artículo 173 del Proyecto. De acuerdo al segundo párrafo de este artículo, el reconocimiento de existencia origina la nulidad del nuevo matrimonio contraido por el cónyuge, considerándose sin embargo a éste como contraido de buena fe, debiendo decidir el cónyuge del reaparecido entre el primer y segundo cónyuge, a fin de contraer un nuevo matrimonio.

Esta posición fue desestimada por la Comisión Revisora pues, como expresa Jack Bigio,"repugna al sentimiento jurídico la idea de que el viudo presunto deba escoger entre dos personas con quienes se casó, para contraer uno nuevo, y además, porque "resulta evidente que no habria ningún medio legal para obligarlo". (65)

Quienes se oponen a la posición asumida en el Código Civil sostienen que si la persona reaparecida puede reivindicar sus bienes de acuerdo al artículo 69, debería recuperar también su estado matrimonial (66).

No coincidimos con este último fundamento, ya que la reivindicación tiene lugar solamente respecto a bienes y el matrimonio es una institución que involucra a personas, no a bienes.

Creemos que este problema debe enfocarse desde una perspectiva no sólo jurídica sino humana $y$, en este sentido, debe considerarse que:

"... por respetable y digna de consideración que sea la situación de aquél a quien se tuvo por fallecido, lo es en mayor medida, la del segundo

(64) FERNANDEZ SESSAREGO, Carlos. Derecho de las... Ob.Cit. P. 137.

(65) BIGIO CHREM, Jack. Ob.Cit. p. 68.

(66) FERNANDEZ SESSAREgO, Carlos. Derecho de las... Ob.Cit. P. 138. 
hogar formado bajo el amparo de una presunción legal razonable y prudente que permite a cualquiera de los cónyuges rehacer su vida y reencontrar en el seno de una nueva familia la felicidad a que todo ser humano tiene derecho" (67).

De los argumentos señalados por Jack Bigio al fundamentar la tesis incorporada al Código Civil por la Comisión Revisora, nos parecen esenciales los siguientes:

1. El hecho de que el cónyuge del declarado muerto contraiga nuevo matrimonio hace suponer, con toda razón, la terminación del vínculo afectivo que lo unía a su anterior cónyuge y la voluntad de iniciar una nueva vida.

2. Que el matrimonio es un acto jurídico puro y simple. De modo que de poder ser invalidado el nuevo matrimonio del cónyuge presente por el reconocimiento de existencia, este matrimonio sería celebrado bajo la condición resolutoria de la reaparición del declarado presuntamente muerto.

3. Es preferible que el derecho mantenga una situación actual antes que provocar su destrucción por una relación matrimonial que en los hechos y en el tiempo ha terminado (68).

En nuestra opinión, la posición incorporada por la Comisión Revisora al Código Civil es acertada por enfocar el problema de manera integral.

Sin embargo, el Código Civil no contempla el caso en que, habiendo contraido nuevo matrimonio el cónyuge presente, existiera mala fe (saber que el declarado muerto se encontraba con vida), en uno o en ambos contrayentes (69).

(67) SOLARI AGUELA, Giancarlo. Ob.Cit. P. 250.

(68) BIGIO CHREM, Jack. Ob.Cit. Pp. 67-68.

(69) EYZAGUIRRE MACCAN, Rolando. La Declaración de Muerte Pre- 
Creemos que debió haberse dispuesto que, de existir mala $\mathrm{fe}$, el reconocimiento de existencia invalida el nuevo matrimonio contraido por el cónyuge del reaparecido.

\section{b) Patria Potestad}

El reconocimiento de existencia permite al reaparecido recuperar el ejercicio de la patria potestad de los hijos menores que tuviera, salvo el caso en que se probara que hubo voluntad de abandono de parte del reaparecido. En tal caso perdería su ejercicio, pues una de las causales de pérdida de la patria potestad la constituye el abandono del hijo durante seis meses continuos o cuando la duración sumada del abandono excede de este plazo (art. 462).

sunta y el Reconocimiento de Existencia en el Código Civil de 1984. Tesis de Bachiller. Lima, Pontificia Universidad Católica del Perú. 1988. Pp. 64-65. 